\title{
T1000: A reduced gene set prioritized for toxicogenomic studies
}

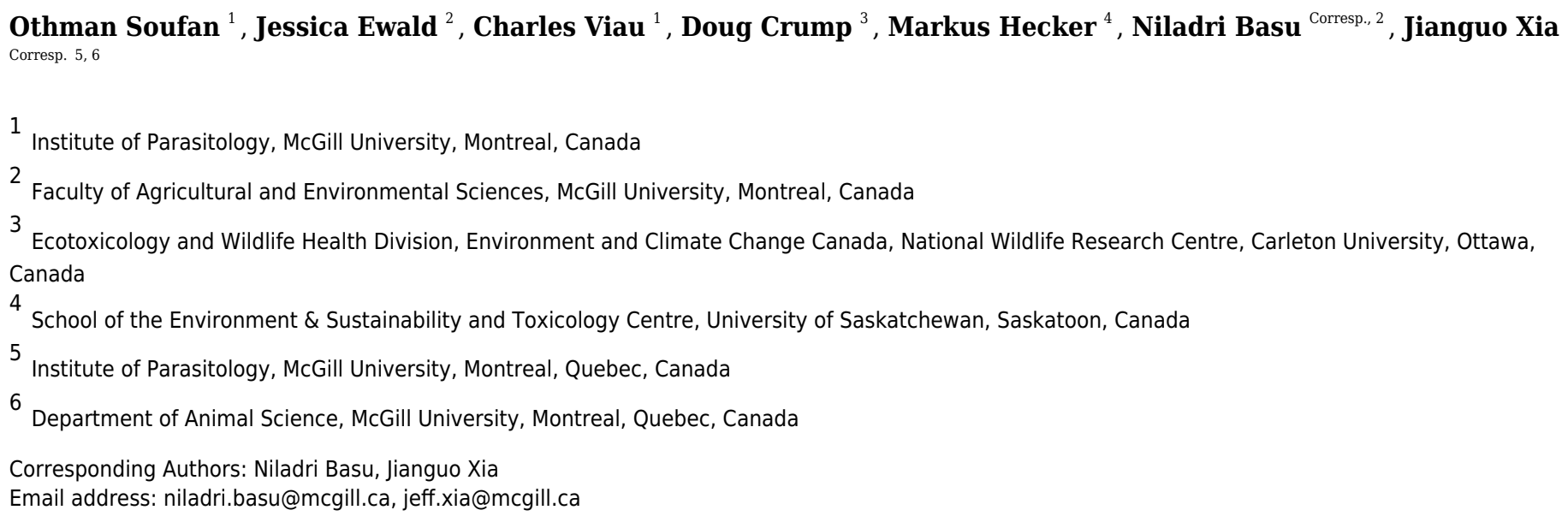

There is growing interest within regulatory agencies and toxicological research communities to develop, test, and apply new approaches, such as toxicogenomics, to more efficiently evaluate chemical hazards. Given the complexity of analyzing thousands of genes simultaneously, there is a need to identify reduced gene sets. Though several gene sets have been defined for toxicological applications, few of these were purposefully derived using toxicogenomics data. Here, we developed and applied a systematic approach to identify 1000 genes (called Toxicogenomics-1000 or T1000) highly responsive to chemical exposures. First, a co-expression network of 11,210 genes was built by leveraging microarray data from the Open TG-GATEs program. This network was then reweighted based on prior knowledge of their biological (KEGG, MSigDB) and toxicological (CTD) relevance. Finally, weighted correlation network analysis was applied to identify 258 gene clusters. T1000 was defined by selecting genes from each cluster that were most associated with outcome measures. For model evaluation, we compared the performance of T1000 to that of other gene sets (L1000, S1500, Genes selected by Limma, and random set) using two external datasets based on the rat model. Additionally, a smaller (T384) and a larger version (T1500) of T1000 were used for dose-response modeling to test the effect of gene set size. Our findings demonstrated that the T1000 gene set is predictive of apical outcomes across a range of conditions (e.g., in vitro and in vivo, dose-response, multiple species, tissues, and chemicals), and generally performs as well, or better than other gene sets available. 


\section{T1000: A reduced gene set prioritized for toxicogenomic studies}

$2{ }^{1}$ Othman Soufan, ${ }^{2}$ Jessica Ewald, ${ }^{1}$ Charles Viau, ${ }^{3}$ Doug Crump, ${ }^{4}$ Markus Hecker, ${ }^{2, *}$ Niladri Basu

3 and $1,5,{ }^{*}$ Jianguo Xia

$4 \quad{ }^{1}$ Institute of Parasitology, McGill University, Montreal, Quebec, Canada; ${ }^{2}$ Faculty of

5 Agricultural and Environmental Sciences, McGill University, Montreal, Quebec, Canada;

6 3 Ecotoxicology and Wildlife Health Division, Environment and Climate Change Canada,

7 National Wildlife Research Centre, Carleton University, Ottawa, Canada; ${ }^{4}$ School of the

8 Environment \& Sustainability and Toxicology Centre, University of Saskatchewan, Saskatoon,

9 Canada; ${ }^{5}$ Department of Animal Science, McGill University, Montreal, Quebec, Canada.

$11 *$ *orrespondance: Niladri Basu

12 Email: niladri.basu@mcgill.ca

13 Tel: (514) $398-8642$

14 Address: CINE Building,

H9X 3V9.

$20 *$ Correspondence: Jianguo Xia

21 Email:_ jeff.xia@mcgill.ca

22 Tel: (514) $398-8668$ 
23 Address: Office P107, Parasitology Building,

2421111 Lakeshore Road

25 Ste. Anne de Bellevue

26 QC, Canada

27

H9X 3V9.

28

29

30

31

Peer] reviewing PDF | (2019:06:38961:2:0:NEW 28 Sep 2019) 


\section{Abstract}

34 There is growing interest within regulatory agencies and toxicological research communities to 35 develop, test, and apply new approaches, such as toxicogenomics, to more efficiently evaluate 36 chemical hazards. Given the complexity of analyzing thousands of genes simultaneously, there is 37 a need to identify reduced gene sets. Though several gene sets have been defined for toxicological applications, few of these were purposefully derived using toxicogenomics data.

39 Here, we developed and applied a systematic approach to identify 1000 genes (called

40 Toxicogenomics-1000 or T1000) highly responsive to chemical exposures. First, a co-

41 expression network of 11,210 genes was built by leveraging microarray data from the Open TG-

42 GATEs program. This network was then re-weighted based on prior knowledge of their

43 biological (KEGG, MSigDB) and toxicological (CTD) relevance. Finally, weighted correlation

44 network analysis was applied to identify 258 gene clusters. T1000 was defined by selecting

45 genes from each cluster that were most associated with outcome measures. For model evaluation,

46 we compared the performance of T1000 to that of other gene sets (L1000, S1500, Genes selected

47 by Limma, and random set) using two external datasets based on the rat model. Additionally, a

48 smaller (T384) and a larger version (T1500) of T1000 were used for dose-response modeling to

49 test the effect of gene set size. Our findings demonstrated that the T1000 gene set is predictive of

50 apical outcomes across a range of conditions (e.g., in vitro and in vivo, dose-response, multiple

51 species, tissues, and chemicals), and generally performs as well, or better than other gene sets

52 available. 


\section{Introduction}

55 Over the past decade there have been profound steps taken across the toxicological sciences and 56 regulatory communities to help transform conventional toxicity testing largely based on animal

57 models and apical outcome measurements to an approach that is founded on systems biology and 58 predictive science (Kavlock et al. 2018; Knudsen et al. 2015; Villeneuve \& Garcia-Reyero

59 2011). On the scientific side, efforts are being exemplified by emergent notions such as the 60 Adverse Outcome Pathway framework (AOP; Ankley et al., 2010) and New Approach Methods

61 (ECHA 2016). On the regulatory side, these are exemplified by changes to, for example,

62 chemical management plans in Canada, the United States and REACH (ECHA 2007) across the 63 European Union.

65 A core tenet underlying the aforementioned transformations, as catalyzed by the 2007 U.S.

66 National Research Council report "Toxicity Testing in the $21^{\text {st }}$ Century” (Andersen \& Krewski

67 2009), is that perturbations at the molecular-level can be predictive of those at the whole

68 organism-level. Though whole transcriptome profiling is increasingly popular, it still remains

69 costly for routine research and regulatory applications. Additionally, building predictive models

70 with thousands of features introduces problems due to the high dimensionality of the data and so

71 considering a smaller number of genes has the potential to increase classification performance

72 (Alshahrani et al. 2017; Soufan et al. 2015b). Identifying smaller panels of key genes that can be

73 measured, analyzed and interpreted conveniently remain an appealing option for toxicological

74 studies and decision making 
76 In recent years, several initiatives across the life sciences have started to identify reduced gene

77 sets from whole transcriptomic studies. For example, the Library of Integrated Network-Based

78 Cellular Signatures (LINCS) project derived L1000, which is a gene set of 976 'Landmark'

79 genes chosen to infer the expression of 12,031 other highly connected genes in the human

80 transcriptome (Subramanian et al. 2017). In the toxicological sciences, the U.S. Tox21 Program

81 recently published $\mathrm{S} 1500+$, which is a set of 2,753 genes designed to be both representative of

82 the whole-transcriptome, while maintaining a minimum coverage of all biological pathways in

83 Kyoto Encyclopedia of Genes and Genomes (KEGG) (Kanehisa et al. 2007) and Molecular

84 Signatures Database (MSigDB) (Liberzon et al. 2015a). The first 1,500 genes were selected by

85 analyzing microarray data from 3,339 different studies, and the rest were nominated by members

86 of the scientific community (Mav et al. 2018). L1000 and S1500 gene sets were originally

87 proposed to serve a different purpose. The 978 landmark genes of L1000 are chosen to infer

88 expression of other genes more accurately, while genes of S1500 are selected to achieve more

89 biological pathway coverage. Compared to L1000, the S1500 gene set attains more toxicological

90 relevance through the gene nomination phase, though its data-driven approach relies upon

91 microarray data primarily derived from non-toxicological studies. It worth nothing that about

$9233.7 \%$ of genes are shared between both signatures. Even though some differences can be

93 realized between L1000 and S1500, they are both strong candidates of gene expression modeling

94 and prediction (Haider et al. 2018).

95

96 The objectives of the current study were to develop and apply a systematic approach to identify

97 highly-responsive genes from toxicogenomic studies, and from these to nominate a set of 1000

98 genes to form the basis for the T1000 (Toxicogenomics-1000) reference gene set. Co-expression 
99 network analysis is an established approach using pairwise correlation between genes and

100 clustering methods to group genes with similar expression patterns (van Dam et al. 2018). First, a

101 co-expression network was derived using in vitro and in vivo data from human and rat studies

102 from the Toxicogenomics Project-Genomics Assisted Toxicity Evaluation System (Open TG-

103 GATEs) database. Next, the connections within the co-expression network were adjusted to

104 increase the focus on genes in KEGG pathways, the MSigDB, or the Comparative

105 Toxicogenomics Database (CTD) (Davis et al. 2017). This incorporation of prior biological and

106 toxicological knowledge was motivated by loose Bayesian inference to refine the

107 computationally-prioritized transcriptomic space. Clusters of highly connected genes were

108 identified from the resulting co-expression network, and machine learning models were applied

109 to prioritize clusters based on their association with apical endpoints. Clustering genes based on

110 expression data has been shown to be instrumental in functional annotation and sample

111 classification (Necsulea et al. 2014), with the rationale that genes with similar expression

112 patterns are likely to participate in the same biological pathways (Budinska et al. 2013). From

113 each cluster key genes were identified for inclusion in T1000. Testing and validation of T1000

114 was realized through two separate datasets (one from Open TG-GATEs and one from the U.S.

115 National Toxicology Program) that were not used for gene selection. The current study is part of

116 the larger EcoToxChip project (Basu et al. 2019). For the processed data, user can download all

117 samples processed from https://zenodo.org/record/3359047\#.XUcTwpMzZ24. We also deposited

118 source codes and scripts used for the study at https://github.com/ecotoxxplorer/t1000. 


\section{Materials \& Methods}

\section{Databases and datasets preparation}

121 The derivation of T1000 was based on five public microarray datasets of toxicological relevance

122 (Table 1): four datasets from Open TG-GATEs (Igarashi et al. 2014b), and one dataset generated

123 by Thomas et al (referred to as the dose-response dataset in this manuscript; GSE45892) (Thomas

124 et al. 2013). Table 1 provides a summary of all microarray datasets used in this study. For building

125 the initial T1000 gene set, we used three of the four Open TG-GATEs datasets (see datasets 1-3 in 126 Table 1).

127

128

129

130

131

132

133

134 141 analysis.

\section{Open TG-GATEs}

Open TG-GATEs is one of the largest publicly accessible toxicogenomics resources (Igarashi et al. 2014b). This database comprises data from 170 compounds (mostly drugs) with the aim of improving and enhancing drug safety assessment. It contains gene expression profiles and traditional toxicological data derived from in vivo (rat) and in vitro (primary rat hepatocytes and primary human hepatocytes) studies. To process the raw gene expression data files of Open TGGATEs, the Affy package (Gautier et al. 2004) was used to produce Robust Multi-array Average (RMA) probe set intensities (Irizarry et al. 2003b). Gene annotation for human and rat was performed using Affymetrix Human Genome U133 Plus 2.0 Array annotation data and Affymetrix Rat Genome 230 2.0 Array annotation data, respectively. Genes without annotation were excluded. When the same gene was mapped multiple times, the average value was used. Finally, all profiles for each type of experiment were joined into a single matrix for downstream 
142 From the training datasets, specific samples were labelled binary as "dysregulated" or "non-

143 dysregulated". Dysregulated refers to exposure cases with potential toxic outcomes and non-

144 dysregulated included controls and exposures with non-toxic outcomes. For the in vitro datasets,

145 gene expression changes were associated with lactate dehydrogenase (LDH) activity (\%). The

146 activity of LDH, which serves as a proxy for cellular injury or dysregulation, was binarized such

147 that values above $105 \%$ and below 95\% were considered "dysregulated". While conservative,

148 we note that these cut-off values were situated around the $5 \%$ and $95 \%$ marks of the LDH

149 distribution curve (see Supplemental Figure S1 and Supplemental Information S1 for more

150 details).

151

152 For the in vivo datasets (kidney and liver datasets from Open TG-GATEs), gene expression

153 changes were associated with histopathological measures. The magnitude of pathologies was

154 previously annotated into an ordinal scale: present, minimal, slight, moderate and severe

155 (Igarashi et al. 2014a). This scale was further reduced into a binary classification with the first

156 three levels considered "non-dysregulated" while the latter two were considered "dysregulated".

\section{Dose-response dataset and benchmark dose (BMD) calculation}

159 The dose-response dataset (Accession No. GSE45892), was used to externally evaluate the 160 ability of T1000 genes to predict apical endpoints (Thomas et al. 2013). Briefly, this dataset

161 contains Affymetrix HT Rat230 PM microarray data following in vivo exposure of rats to six

162 chemicals (TRBZ: 1,2,4-tribromobenzene, BRBZ: bromobenzene, TTCP: 2,3,4,6-

163 tetrachlorophenol, MDMB: 4,4'-methylenebis( $N, N^{\prime}$-dimethyl)aniline, NDPA: N-

164 nitrosodiphenylamine, and HZBZ: hydrazobenzene). In exposed animals, both gene expression 165 and apical outcomes (liver: absolute liver weight, vacuolation, hypertrophy, microvesiculation, 
166 necrosis; thyroid: absolute thyroid weight, follicular cell hypertrophy, follicular cell hyperplasia;

167 bladder: absolute bladder weight, increased mitosis, diffuse transitional epithelial hyperplasia,

168 increased necrosis epithelial cell) were measured, permitting the comparison of transcriptionally-

169 derived benchmark doses $\left(\mathrm{BMD}_{\mathrm{t}}\right)$ with traditional benchmark doses derived from apical

170 outcomes (Yang et al. 2007). The apical outcome-derived benchmark dose $\left(\mathrm{BMD}_{\mathrm{a}}\right)$ for each

171 treatment group was defined as the benchmark dose from the most sensitive apical outcome for

172 the given chemical-duration group.

173 Raw gene expression data (CEL files) for the dose-response dataset were downloaded from GEO

174 (Accession No. GSE45892), organized into chemical-exposure-duration treatment groups, and

175 normalized using the RMA method (Irizarry et al. 2003a). Only expression measurements

176 corresponding to genes in the T1000 gene (or T384 and T1500) set were retained, resulting in

177 reduced gene expression matrices for each treatment group $(t=24)$. The reduced gene

178 expression matrices were analyzed using BMDExpress 2.0 to calculate a toxicogenomic

179 benchmark dose $\left(\mathrm{BMD}_{\mathrm{t}}\right)$ for each treatment group (Yang et al. 2007). Here, the $\mathrm{BMD}_{\mathrm{t}}$ was

180 calculated as the dose that corresponded to a $10 \%$ increase in gene expression compared to the

181 control (Farmahin et al. 2017). Within BMDExpress 2.0, genes were filtered using one-way

182 ANOVA (FDR adjusted $\mathrm{p}$-value cut-off $=0.05) . \mathrm{A} \mathrm{BMD}_{\mathrm{t}}$ was calculated for each differentially

183 expressed gene by curve fitting with exponential (degree 2-5), polynomial (degree 2-3), linear,

184 power, and Hill models. For each gene, the model with the lowest Akaike information criterion

185 (AIC) was used to derive the $\mathrm{BMD}_{\mathrm{t}}$.

186

187 The $\mathrm{BMD}_{\mathrm{t}} \mathrm{s}$ from individual genes were used to determine a treatment group-level $\mathrm{BMD}_{\mathrm{t}}$ using

188 functional enrichment analysis with Reactome pathways (Farmahin et al. 2017). Note, we chose 
189 here to functionally enrich with Reactome since we utilized KEGG to derive the T1000 list.

190 After functional enrichment analysis, significantly enriched pathways $(\mathrm{p}$-value $<0.05)$ were

191 filtered such that only pathways with $>3$ genes and $>5 \%$ of genes in the pathway were retained.

192 The treatment group-level $\mathrm{BMD}_{\mathrm{t}}$ was calculated by considering the mean gene-level $\mathrm{BMD}_{\mathrm{t}}$ for

193 each significantly enriched pathway and selecting the lowest value. If there were no significantly

194 enriched pathways that passed all filters, no $\mathrm{BMD}_{\mathrm{t}}$ could be determined for that treatment group.

195 The similarity of the $\mathrm{BMD}_{\mathrm{t}}$ to the benchmark dose derived from apical outcomes $\left(\mathrm{BMD}_{\mathrm{a}}\right)$ was

196 assessed by calculating the $\mathrm{BMD}_{\mathrm{t}} / \mathrm{BMD}_{\mathrm{a}}$ ratio and the correlation between $\mathrm{BMD}_{\mathrm{t}}$ and $\mathrm{BMD}_{\mathrm{a}}$ for

197 all treatment groups (Farmahin et al. 2017). Following the same procedures, $\mathrm{BMD}_{\mathrm{t}} / \mathrm{BMD}_{\mathrm{a}}$ ratio

198 and correlation statistics were determined from genes belonging to L1000, S1500, and Linear

199 Models for Microarray Data (Limma) (Smyth 2005) to provide a reference for the performance

200 of T1000 genes.

201

202 Databases for Computing Prior Knowledge

203 The CTD, KEGG, and Hallmark databases were mined to integrate existing toxicogenomics and

204 broader biological knowledge into one network that represents the prior knowledge space. CTD is

205 manually curated from the literature to serve as a public source for toxicogenomics information,

206 currently including over 30.5 million chemical-gene, chemical-disease, and gene-disease

207 interactions (Davis et al. 2017). Following the recommendations of $\mathrm{Hu}$ et al. (2015), only

208 "mechanistic/marker" associations were extracted from the CTD database, thus excluding

209 "therapeutic" associations that are presumably less relevant to toxicology. The extracted subgraph

210 contained 2,889 chemicals, 950 diseases annotated as toxic endpoints (e.g. neurotoxicity,

211 cardiotoxicity, hepatotoxicity and nephrotoxicity), and 22,336 genes. KEGG pathways are a 
212 popular bioinformatics resource that help to link, organize, and interpret genomic information

213 through the use of manually drawn networks describing the relationships between genes in specific

214 biological processes (Kanehisa et al. 2007). The MSigDB Hallmark gene sets have been developed

215 using a combination of automated approaches and expert curation to represent known biological

216 pathways and processes while limiting redundancy (Liberzon et al. 2015b).

217 Each feature vector consisted of 239 dimensions, representing information encoded from

218 Hallmark, KEGG and CTD. For the Hallmark and KEGG features, we used "1" or " 0 " to

219 indicate if a gene was present or absent for each of the 50 Hallmark gene sets (Liberzon et al.

220 2015b) and 186 KEGG pathways (Kanehisa \& Goto 2000). These features were transformed into

221 z-scores. For the CTD features, we computed the degree, betweenness centrality, and closeness

222 centrality of each gene, based on the topology of the extracted CTD subgraph. The topology

223 measures were log-scaled for each gene in the network. The resulting prior knowledge space

224 consisted of a 239-dimension vector for each of the 22,336 genes, with each vector containing 50

225 z-score normalized Hallmark features, 186 z-score normalized KEGG features, and three log226 scaled CTD network features.

227

228 Reactome database

229 To understand the biological space covered by T1000, we analyzed T1000's top enriched 230 Reactome pathways (as KEGG was used to develop T1000). Reactome is a manually curated

231 knowledgebase of human reactions and pathways with annotations of 7,088 protein-coding genes

232 (Croft et al. 2014). 


\section{Performance evaluation}

234 For the performance evaluation and testing phase, we leveraged the fourth dataset from Open

235 TG-GATEs (see dataset 4 in Table 1), which was not used for gene ranking or selection so that it

236 could serve as an external validation dataset. The dose-response dataset was used for an

237 additional external validation (see dataset 5 in Table 1).

238

239 In this step, we applied five supervised machine learning methods to the TG-GATES rat kidney

240 in vivo dataset, with the objective to predict which exposures caused significant "dysregulation",

241 according to the criteria defined in step 4. This dataset was purposefully not used earlier when

242 deriving T1000 so that it could serve later as a validation and testing dataset. The five machine

243 learning models used were K-nearest neighbors (KNN; K = 3) (Cover \& Hart 1967), Decision

244 Trees (DT), Naïve Bayes Classifier (NBC), Quadratic Discriminant Analysis (QDA) and

245 Random Forests (RF).

246

247 The performance of each method was evaluated with five-fold cross-validation and measured

248 using six different metrics (Equations $2-7$ ). TP represents the number of true positives, FP the

249 number of false positives, TN the number of true negatives and FN the number of false

250 negatives. The $\mathrm{F}_{1}$ score (also called the balanced $\mathrm{F}$-score) is a performance evaluation measure

251 that computes the weighted average of sensitivity and precision (He \& Garcia 2009), and is well-

252 suited for binary classification models. The $\mathrm{F}_{0.5}$ score (Davis \& Goadrich 2006; Maitin-Shepard

253 et al. 2010; Santoni et al. 2010) is another summary metric that gives twice as much weight to

254 precision than sensitivity. The evaluation was performed on a Linux based workstation with 16

255 cores and 64 GB RAM for processing the data and running the experiments. 256 
257 sensitivity $=T P /(T P+F N)$

258 specificity $=T N /(T N+F P)$

259 precision $=T P /(T P+F P)$

260 GMean $=\sqrt{\text { sensitivity } \times \text { specificity }}$

$261 \quad F_{1}$ Score $=2 \times \frac{\text { precision } \times \text { sensitivity }}{\text { precision }+ \text { sensitivity }}$

$262 \quad F_{0.5}$ Score $=1.25 \times \frac{\text { precision } \times \text { sensitivity }}{0.25 \times \text { precision }+ \text { sensitivity }}$

263

264 Proposed T1000 Framework

265 The work of T1000 was conducted in four discrete phases as follows (see Figure 1): I) data

266 preparation and gene co-expression network generation; II) network clustering to group relevant

267 genes; III) gene selection and prioritization; and IV) external testing and performance evaluation.

268 The goal of phase I was to construct two network representations of the interactions between

269 toxicologically-relevant genes, with one based on TG-GATES microarray data (step 1\&2) and

270 the other based on the KEGG, MSigDB, and CTD databases (step 3). In a co-expression

271 network, nodes represent genes and edges represent the Pearson's correlation of expression

272 values of pairs of genes. In the current study, we constructed three separate co-expression

273 networks using gene expression profiles from Open TG-GATEs datasets (human in vitro, rat in

274 vitro, and rat in vivo) (Table 1). If an interaction with a correlation coefficient of $60 \%$ or higher

275 was present in all three networks, that gene-gene interaction was then accepted and mapped into

276 one integrated co-expression network by averaging the absolute values of the pairwise

277 correlation coefficients between individual genes. Matching between rat and human genes was

278 based on gene symbols (e.g., Ddr1 in rat is matched with DDR1 in human using BiomaRt R

279 package (Durinck et al. 2009)) and ignored when no match exists. This is a more conservative 
280 approach to maintain perfect matching orthologues in the networks although other computational 281 approaches to match orthologues can be used (Wang et al. 2015). The final integrated co-

282 expression network had 11,210 genes from a total of 20,502 genes.

283 To build the prior knowledge space (step 3), we encoded information from the Hallmark, KEGG 284 and CTD databases into feature vectors composed of 239 features describing each gene (see

285 Materials section). Then, we projected the data onto a two-dimensional space using principle 286 component analysis $(\mathrm{PCA})$ and clustered using $\mathrm{K}$-means $(\mathrm{K}=3)$ to detect those genes that

287 contributed most to the prior knowledge space. Regarding K-means, we initially experimented

288 with $\mathrm{K}=1, \mathrm{~K}=3$ and $\mathrm{K}=5$ and after visual inspection of summarized information as

289 Supplemental Information S2 Figure 1, we chose K=3.

290 Genes that were furthest from the centroids (i.e., highest contributing ones) of the K-means

291 clusters were more enriched with pathways and gene-chemical-disease interactions (see

292 Supplemental Information S2). Based on step 3, a ranked list of all genes was generated such 293 that the first ranked gene would have a prior score of $100 \%$ and the last, a prior score close to $2940 \%$. In phase II, we re-weighted the interactions in the co-expression network based on the prior 295 knowledge space and then detected clusters of highly connected genes in the updated network 296 (step 4). In a Bayesian fashion, the pairwise connections between genes in the co-expression 297 network were re-weighted by multiplying the correlation with the mean prior score. For example, 298 given $P(A)$ and $P(B)$ as prior scores of genes $\mathrm{A}$ and $\mathrm{B}$, the correlation score $S(A, B)$ is re299 weighted as follows (Eq. 7):

300

301

$S(A, B)_{\text {new }}=S(A, B) *((P(A)+P(B)) / 2)(7)$ 
303 It should be noted that in Eq. 7, the product of joint distribution could have been considered for

304 the update such that $S(A, B)_{\text {new }}=S(A, B) *((P(A) * P(B))$.

305 After re-weighting the connections, we detected clusters of highly connected genes using the

306 Markov Cluster Algorithm (MCL) (Van Dongen \& Abreu-Goodger 2012). The MCL approach

307 groups together nodes with strong edge weights and then simulates a random flow through a

308 network to find more related groups of genes based on the flow's intensity of movement. It does

309 not require the number of clusters to be pre-specified. An inflation parameter controls the

310 granularity of the output clustering and several values within a recommended range (1.2-5.0)

311 were tried (Van Dongen \& Abreu-Goodger 2012). To optimize for the granularity of the

312 clustering, a systematic analysis for the MCL inflation parameter was performed with values in

313 range (1.2-5.0) (see Supplemental Information S3). After examining closely efficiency and

314 mass fraction, a value of 3.3 was chosen. This generated 258 clusters that consisted of 11,210

315 genes. The average number of genes in each cluster was 43.4 with the min-max ranging from 1

316 to 8,423 .

317 The goal of phase III of gene selection and prioritization was to select the top genes from each

318 cluster to form T1000 (step 5), and then produce a final ranking of the 1000 selected genes (step

319 6). For each of the 258 gene clusters, random forest (RF) classifiers were used to rank genes

320 based on their ability to separate changes in gene expression labelled as "dysregulated" from

321 those labelled "non-dysregulated", using the Gini impurity index of classification (Nguyen et al.

322 2013; Qi 2012; Tolosi \& Lengauer 2011). RF is one of the most widely used solutions for feature

323 ranking, and as an ensemble model, it is known for its stability (Chan \& Paelinckx 2008). In

324 order to cover more biological space and ensure selected genes represent the whole 
325 transcriptome, a different RF classifier is built for each cluster and used to select representative

326 genes (Sahu \& Mishra 2012).

327 We selected the top genes from each cluster based on the performance of the RF classifier. For

328 example, when selecting the 1,000 top genes from two clusters (A and B), if the cross-validation

329 prediction accuracy estimated for models A and B were $60 \%$ and $55 \%$, respectively, then 522

$330((60 \% /(60 \%+55 \%)) * 1000)$ and $478((55 \% /(60 \%+55 \%)) * 1000)$ genes would be selected from

331 clusters A and B. However, if cluster A contained only 520 genes, the remaining two genes

332 would be taken from group B, if possible. So, the cluster size is only used if it contains

333 insufficient genes. We repeated this process until 1000 genes were selected._After choosing top $k$

334 genes from each cluster, we aggregated them into a single list of 1000 genes and built a final RF

335 model to get a global ranking of the genes. We refer to this final ranked list as T1000 (see

336 Supplemental Table S1 for a full list of selected genes and summary annotation; see

337 Supplemental Information S4 for the cluster assignment of the genes). The goal of phase IV

338 was to test the performance of the T1000 gene set using external datasets, and thus transition

339 from gene selection activities to ones that focus on the evaluation of T1000. Phase IV is

340 discussed in the following Results section. To discuss factors that characterizes and distinguishes

$341 \mathrm{~T} 1000$ from L1000 and S1500, Table 2 is provided. As summarized in Table 2, T1000 is more

342 toxicogenomic tailored by selecting genes that optimizes for endpoint predictions and using

343 toxicogenomic datasets. Incorporating the prior knowledge space is critical for T1000 in ranking

344 genes with more contribution to toxic effects. L1000 aims at finding a set of genes that can be

345 used to extrapolate for the full expression space of all other genes. S1500 has considered an

346 optimization for the number of covered pathways. T1000, L1000 and S1500 have considered 
347 using PCA and clustering during the selection process. In T1000, however, this step is part of

348 computing the prior only.

349

350

\section{Results}

351

352

353

354

355

356

357

358

359

360

361

362

363

364

365

366

367

368

369

\section{Overview of T1000 and biological relevance}

The genes comprising T1000 cover a wide biological space of toxicological relevance. For illustration, co-expression networks, before and after applying Steps 2 and 3 (i.e., networks built on the Open TG-GATEs data that are subsequently updated with prior information from KEGG, MSigDb, and CTD), are shown in Figure 2. In part (a) of Figure 2, a sample co-expression network composed of 150 genes (i.e., 150 for visualization purposes only; of the 11,210 genes identified) has, in general, similar color and size of all the nodes of the network. While this covers a broad toxicological space, it does not necessarily identify or prioritize the most important genes. After subjecting the data to steps 2 and 3, two clusters of genes with different node sizes and colors were identified (Figure 2b). Through this refined network, we then applied a prediction model to each cluster to identify the most representative genes resulting in the final co-expression network of the T1000 genes (Figure 2c).

The complete list of T1000 genes with their gene symbols and descriptions, as well as their regulation state (up- or down-regulated) is provided in Supplemental Table S1.

Visual examination of the Reactome enrichment map (Supplemental Figure S2) reveals that 'biological oxidations' (largest circle in Supplemental Figure S2) contained the most enriched pathways followed by 'fatty acid metabolism'. This is logical given that xenobiotic and fatty acid 
370 metabolism, mediated by cytochrome P450 (CYP450) enzymes, feature prominently across the

371 toxicological literature (Guengerich 2007) (Hardwick 2008).

372

373 We further examine two genes that are ranked among the top up- and down-regulated gene sets, 374 respectively. We observed that CXCL10 (ranked $2^{\text {nd }}$ in up-regulated genes) and IGFALS (ranked

$3753^{\text {rd }}$ in down-regulated genes) had reported links in the literature in response to exposure to toxic 376 compounds. Upregulation of CXCL10, the ligand of the chemokine receptor CXCR3 found on

377 macrophages, has been observed in the bronchiolar epithelium of patients with Chronic

378 Obstructive Pulmonary Disease (COPD) compared to non-smokers or smokers with normal lung

379 function (Saetta et al. 2002). Smokers develop COPD after exposure to the many chemicals found

380 in cigarette smoke, which include oxidants that cause inflammation (Foronjy \& D'Armiento 2006).

381 Although TG-GATEs does not comprise any cigarette toxicants within its database, the general

382 pathways by which toxicants disrupt tissue function are represented by T1000.

383 A gene that was found to be significantly downregulated by T1000 was the gene encoding for

384 Insulin Like Growth Factor Binding Protein Acid Labile Subunit or IGFALS, which is an Insulin

385 growth factor-1 (IGF-1) binding protein (Amuzie \& Pestka 2010). Interestingly, the mRNA

386 expression of IGFALS was reported to be significantly downregulated when experimental animals

387 were fed deoxynivalenol, a mycotoxin usually found in grain (Amuzie \& Pestka 2010). By

388 reducing IGFALS, the half-life of circulating IGF-1 is reduced, causing growth retardation

389 (Amuzie \& Pestka 2010). Many compounds in the TG-GATEs database are of organismal origin,

390 and thus, as the data suggest, they have a similar mode of action as deoxynivalenol in reducing

391 expression of important effectors such as IGFALS. 
393 Regarding potential clinical applications, we discuss the use of T1000 signature for screening

394 drugs that may show toxic adverse effects in Supplemental Information S5. The experiment is

395 motivated by the connectivity map project for connecting small molecules, genes, and disease

396 using gene-expression signatures (Lamb et al. 2006).

397

398

\section{Benchmark dose-response results}

399

400

Overall, the aim of the evaluation was to assess the ability of T1000 gene sets to predict apical

401 outcomes according to previously published methods (Farmahin et al. 2017). Additionally, we

repeated step 4 of the T1000 approach to select the top 384 (T384; i.e., a number conducive to 403 study in a QCPR microplate format as per the EcoToxChip project; (Basu et al. 2019)) and 1,500

(T1500 see Supplemental Information S6; i.e., a number pursued in other endeavours like

S1500) genes to investigate the effect of gene set size on apical outcome prediction. To benchmark the performance of T1000 against other notable gene sets, we considered S1500 (Merrick et al. 2015) and L1000 (Subramanian et al. 2017).

408

409

410

411

412

413 (benchmark dose, apical outcome) did not exist due to a lack of observed toxicity (Table 3). The

414 T384 gene set performed similarly with Limma; however, increasing the size of this gene set to

415 T1000 resulted in performance evaluation metrics that rivaled that of all other gene sets of the

416 same size or larger (L1000, Limma, and S1500). Further increasing the size of T1000 to T1500

417 did not increase the performance as the correlation slightly decreased while the average ratio of 
$418 \mathrm{BMD}_{\mathrm{t}} / \mathrm{BMD}_{\mathrm{a}}$ got slightly closer to one. Figure 3 provides a visual summary of the comparison

419 based on the $\mathrm{BMD}_{\mathrm{t}} / \mathrm{BMD}_{\mathrm{a}}$ ratios.

420

421 Prediction results

422 In a second validation study, we applied T1000 to study the Rat Genome 2302.0 Array for

423 Kidney dataset from the Open TG-GATEs program. This dataset was not included in any model

424 training or parameter tuning steps. This helped to establish another external validation of T1000

425 in terms of its generalized ability to predict apical outcomes for datasets derived from different

426 tissues. When compared to baseline gene sets mapped using Limma and L1000, T1000 achieved

427 a relative improvement of the $\mathrm{F}_{1}$ Score by $6.9 \%$ and $27.56 \%$, respectively, thus outperforming

428 comparison gene sets (Table 4). When considering the absolute difference of $\mathrm{F}_{1}$ Score between

429 T1000 and the second best (i.e., Limma), T1000 achieved an improvement of 1.59\%. The

430 improvement was $1.54 \%$ for $\mathrm{F}_{0.5}$ Score confirming that $\mathrm{T} 1000$ led to fewer false positive

431 predictions.

432 Another baseline we compare with is Random-500, where a set of 1000 features are selected

433 randomly and the performance is reported for the five classifiers considered (i.e., LDA, NBC,

$434 \mathrm{KNN}$, QDA and RF). This experiment is repeated for 500 times and the average and standard

435 deviation scores are reported in Table 4. GMean, F1Score and F0.5Score of T1000 are

436 significantly higher $(\mathrm{t}$-test with alpha $=0.1)$ than the random scores. The t-test we performed was

437 based on the average performance of the five used different machine learning (ML) classifiers.

438 So, we averaged results of Random-500 to get a summary performance scores for each of the

439 classifiers. One observation is that the Random-500 results outperformed several gene sets. This

440 can be due to the fact that some machine learning models are less sensitive to the type of selected 
441 features (e.g., RF). On average, we found that a randomly generated set would outperform other

442 models with a chance of about $30 \%$ only. Here, we focused on F0.5Measure as one of the

443 summary performance measures. It should be noted that this does not reflect the magnitude of

444 improvement which is measured using the t-test. Given the fact that other approaches will

445 outperform a random selection in $70 \%$ and with a significantly higher performance on average

446 (see T1000 in Table 4), we conclude that a systematic approach is required to prioritize genes.

447 In the context of high throughput screening, such small improvements in $\mathrm{F}_{1}$ Score or $\mathrm{F}_{0.5}$ Score

448 may represent large cost savings (Soufan et al. 2015a) as false positives may lead to added

449 experiments that would otherwise be unnecessary. Detailed performance scores of each

450 individual machine learning model are provided in Supplemental Table S2. Please refer to

451 Supplemental Information S7 for more comparisons including expression space visualization 452 using PCA and gene set coverage evaluation.

453

454 Discussion

455 There is great interest across the toxicological and regulatory communities in harnessing 456 transcriptomics data to guide and inform decision-making (Basu et al. 2019; Council 2007;

457 ECHA 2016; Mav et al. 2018; Thomas et al. 2019). In particular, transcriptomic signatures hold 458 great promise to identify chemical-specific response patterns, prioritize chemicals of concern,

459 and predict quantitatively adverse outcomes of regulatory concern, in a cost-effective manner.

460 However, the inclusion of full transcriptomic studies into standard research studies faces

461 logistical barriers and bioinformatics challenges, and thus, there is interest in the derivation and 462 use of reduced but equally meaningful gene sets. 
464 Our approach to select T1000 followed the same rationale of how the LINCS program derived

465 the L1000 dataset (Liu et al. 2015), though here we purposefully included additional steps to

466 bolster the toxicological relevance of the resulting gene set. Generating a list of ranked genes

467 based on toxicologically relevant input data and prior knowledge is another key feature of $468 \mathrm{~T} 1000$.

469 There are some limitations associated with our current study. For instance, the co-expression 470 network was based on data from the Open TG-GATEs program. While this is arguably the 471 largest toxicogenomics resource available freely, the program is founded on one in vivo model 472 (rat), two in vitro models (primary rat and human hepatocytes), 170 chemicals that are largely 473 drugs, and microarray platforms. Thus, there remain questions about within- and cross- species 474 and cell type differences, the environmental relevance of the tested chemicals, and the biological 475 space captured by the microarray. The multi-pronged and -tiered bioinformatics approach was 476 designed to yield a toxicologically robust gene set, and the approach can be ported to other 477 efforts that are starting to realize large toxicogenomics databases such as our own EcoToxChip 478 project (Basu et al. 2019). In addition, our approach in selecting T1000 genes was purely data479 driven without considering input from scientific experts as was done by the NTP to derive the 480 S1500 gene set (Mav et al. 2018). It is unclear how such gene sets (e.g., T1000, S1500) will be 481 used by the community and under which domains of applicability, and thus there is a need to 482 perform case studies in which new approach methods are compared to traditional methods 483 (Kavlock et al. 2018). It worth to mention that T1000 had 259 and 90 genes in common with 484 S1500 and L1000, respectively and 741 unique genes.

485

\section{Conclusions}


487 Here we outlined a systematic, data-driven approach to identify highly-responsive genes from 488 toxicogenomics studies. From this, we prioritized a list of 1,000 genes termed the T1000 gene 489 set. We demonstrated the applicability of T1000 to 7,172 expression profiles, showing great 490 promise in future applications of this gene set to toxicological evaluations. We externally 491 validated T1000 against two in vivo datasets of toxicological prominence (a kidney dataset of 492308 experiments on 41 chemicals from Open TG-GATEs and a dose-response study of 30 493 experiments on six chemicals (Thomas et al. 2013). We compared the performance of T1000 494 against existing gene sets (Limma, L1000 and S1500) as well as panels of randomly selected 495 genes. In doing so, we demonstrate T1000's versatility as it is predictive of apical outcomes 496 across a range of conditions (e.g., in vitro and in vivo), and generally performs as well, or better 497 than other gene sets available. Our approach represents a promising start to yield a 498 toxicologically-relevant gene set. We hope that future efforts will start to use and apply T1000 499 in a diverse range of settings, and from these we can then start to make updates to the 500 composition of the T1000 gene set based on improved understanding of its performance 501 characteristics and user experiences. 


\section{Supplemental data}

504 Supplemental data are available at PeerJ online.

505

506

507

508

509

510

511

512

513

514

515

516

517

518

\section{Acknowledgements}

We acknowledge the support of all members of the EcoToxChip project as well as the project's

financial sponsors (Genome Canada, Génome Québec, Genome Prairie, the Government of

Canada, Environment and Climate Change Canada, Ministère de l'Économie, de la Science et de l'Innovation du Québec, the University of Saskatchewan, and McGill University). We are grateful to the guidance offered by our project's program officer (Micheline Ayoub,

Génome Québec) and members of our Research Oversight Committee (Chair: Nancy Denslow; Members: Kevin Crofton, Dan Schlenk, Roy Suddaby, and Carole Yauk).

\section{Funding}

This study was funded by Genome Canada, Génome Québec, Genome Prairie, the Government of Canada, Environment and Climate Change Canada, Ministère de l'Économie, de la Science et de l'Innovation du Québec, the University of Saskatchewan, and McGill University.

\section{References}

Alshahrani M, Soufan O, Magana-Mora A, and Bajic VB. 2017. DANNP: an efficient artificial neural network pruning tool. PeerJ Computer Science 3:e137.

Amuzie CJ, and Pestka JJ. 2010. Suppression of insulin-like growth factor acid-labile subunit expression--a novel mechanism for deoxynivalenol-induced growth retardation. Toxicol Sci 113:412-421. 10.1093/toxsci/kfp225

Andersen ME, and Krewski D. 2009. Toxicity testing in the 21 st century: bringing the vision to life. Toxicol Sci 107:324-330. 10.1093/toxsci/kfn255

Basu N, Crump D, Head J, Hickey G, Hogan N, Maguire S, Xia J, and Hecker M. 2019. EcoToxChip: A next-generation toxicogenomics tool for chemical prioritization and environmental management. Environ Toxicol Chem 38:279-288. 10.1002/etc.4309

Budinska E, Popovici V, Tejpar S, D'Ario G, Lapique N, Sikora KO, Di Narzo AF, Yan P, Hodgson JG, Weinrich S, Bosman F, Roth A, and Delorenzi M. 2013. Gene expression 
534

535

536

537

538

539

540

541

542

543

544

545

546

547

548

549

550

551

552

553

554

555

556

557

558

559

560

561

562

563

564

565

566

567

568

569

570

571

572

573

574

575

576

577

578

579

patterns unveil a new level of molecular heterogeneity in colorectal cancer. $J$ Pathol 231:63-76. 10.1002/path.4212

Chan JC-W, and Paelinckx D. 2008. Evaluation of Random Forest and Adaboost tree-based ensemble classification and spectral band selection for ecotope mapping using airborne hyperspectral imagery. Remote Sensing of Environment 112:2999-3011.

Council NR. 2007. Toxicity testing in the 21st century: a vision and a strategy: National Academies Press.

Cover TM, and Hart PE. 1967. Nearest neighbor pattern classification. Information Theory, IEEE Transactions on 13:21-27.

Croft D, Mundo AF, Haw R, Milacic M, Weiser J, Wu G, Caudy M, Garapati P, Gillespie M, Kamdar MR, Jassal B, Jupe S, Matthews L, May B, Palatnik S, Rothfels K, Shamovsky V, Song H, Williams M, Birney E, Hermjakob H, Stein L, and D'Eustachio P. 2014. The Reactome pathway knowledgebase. Nucleic Acids Res 42:D472-477. 10.1093/nar/gkt1 102

Davis AP, Grondin CJ, Johnson RJ, Sciaky D, King BL, McMorran R, Wiegers J, Wiegers TC, and Mattingly CJ. 2017. The comparative toxicogenomics database: update 2017. Nucleic acids research 45:D972-D978.

Davis J, and Goadrich M. 2006. The relationship between Precision-Recall and ROC curves. Proceedings of the 23rd international conference on Machine learning: ACM. p 233-240.

Durinck S, Spellman PT, Birney E, and Huber W. 2009. Mapping identifiers for the integration of genomic datasets with the R/Bioconductor package biomaRt. Nat Protoc 4:1184-1191. 10.1038/nprot.2009.97

ECHA. 2007. Understanding REACH. Available at https://echa.europa.eu/regulations/reach/understanding-reach (accessed April 11, 2019.

ECHA. 2016. New Approach Methodologies in Regulatory Science. In: Agency EC, editor. European Chemicals Agency (ECHA). Helsinki.

Farmahin R, Williams A, Kuo B, Chepelev NL, Thomas RS, Barton-Maclaren TS, Curran IH, Nong A, Wade MG, and Yauk CL. 2017. Recommended approaches in the application of toxicogenomics to derive points of departure for chemical risk assessment. Archives of toxicology 91:2045-2065.

Foronjy R, and D'Armiento J. 2006. The Effect of Cigarette Smoke-derived Oxidants on the Inflammatory Response of the Lung. Clin Appl Immunol Rev 6:53-72. 10.1016/j.cair.2006.04.002

Gautier L, Cope L, Bolstad BM, and Irizarry RA. 2004. affy--analysis of Affymetrix GeneChip data at the probe level. Bioinformatics 20:307-315. 10.1093/bioinformatics/btg405

Guengerich FP. 2007. Mechanisms of cytochrome P450 substrate oxidation: MiniReview. $J$ Biochem Mol Toxicol 21:163-168.

Haider S, Black MB, Parks BB, Foley B, Wetmore BA, Andersen ME, Clewell RA, Mansouri K, and McMullen PD. 2018. A Qualitative Modeling Approach for Whole Genome Prediction Using High-Throughput Toxicogenomics Data and Pathway-Based Validation. Front Pharmacol 9:1072. 10.3389/fphar.2018.01072

Hardwick JP. 2008. Cytochrome P450 omega hydroxylase (CYP4) function in fatty acid metabolism and metabolic diseases. Biochem Pharmacol 75:2263-2275. 10.1016/j.bcp.2008.03.004

He H, and Garcia EA. 2009. Learning from imbalanced data. Knowledge and Data Engineering, IEEE Transactions on 21:1263-1284. 
580

581

582

583

584

585

586

587

588

589

590

591

592

593

594

595

596

597

598

599

600

601

602

603

604

605

606

607

608

609

610

611

612

613

614

615

616

617

618

619

620

621

622

623

624

625

Igarashi Y, Nakatsu N, Yamashita T, Ono A, Ohno Y, Urushidani T, and Yamada H. 2014a. Open TG-GATEs - Pathological items. Available at https://dbarchive.biosciencedbc.jp/en/open-tggates/data-12.html2017).

Igarashi Y, Nakatsu N, Yamashita T, Ono A, Ohno Y, Urushidani T, and Yamada H. 2014b. Open TG-GATEs: a large-scale toxicogenomics database. Nucleic acids research 43:D921-D927.

Irizarry RA, Bolstad BM, Collin F, Cope LM, Hobbs B, and Speed TP. 2003a. Summaries of Affymetrix GeneChip probe level data. Nucleic acids research 31:e15-e15.

Irizarry RA, Hobbs B, Collin F, Beazer-Barclay YD, Antonellis KJ, Scherf U, and Speed TP. 2003b. Exploration, normalization, and summaries of high density oligonucleotide array probe level data. Biostatistics 4:249-264. 10.1093/biostatistics/4.2.249

Kanehisa M, Araki M, Goto S, Hattori M, Hirakawa M, Itoh M, Katayama T, Kawashima S, Okuda S, and Tokimatsu T. 2007. KEGG for linking genomes to life and the environment. Nucleic acids research 36:D480-D484.

Kanehisa M, and Goto S. 2000. KEGG: kyoto encyclopedia of genes and genomes. Nucleic acids research 28:27-30.

Kavlock RJ, Bahadori T, Barton-Maclaren TS, Gwinn MR, Rasenberg M, and Thomas RS. 2018. Accelerating the Pace of Chemical Risk Assessment. Chem Res Toxicol 31:287-290. 10.1021/acs.chemrestox.7b00339

Knudsen TB, Keller DA, Sander M, Carney EW, Doerrer NG, Eaton DL, Fitzpatrick SC, Hastings KL, Mendrick DL, Tice RR, Watkins PB, and Whelan M. 2015. FutureTox II: in vitro data and in silico models for predictive toxicology. Toxicol Sci 143:256-267. 10.1093/toxsci/kfu234

Lamb J, Crawford ED, Peck D, Modell JW, Blat IC, Wrobel MJ, Lerner J, Brunet JP, Subramanian A, Ross KN, Reich M, Hieronymus H, Wei G, Armstrong SA, Haggarty SJ, Clemons PA, Wei R, Carr SA, Lander ES, and Golub TR. 2006. The Connectivity Map: using gene-expression signatures to connect small molecules, genes, and disease. Science 313:1929-1935. 10.1126/science.1132939

Liberzon A, Birger C, Thorvaldsdottir H, Ghandi M, Mesirov JP, and Tamayo P. 2015a. The Molecular Signatures Database (MSigDB) hallmark gene set collection. Cell Syst 1:417425. 10.1016/j.cels.2015.12.004

Liberzon A, Birger C, Thorvaldsdóttir H, Ghandi M, Mesirov JP, and Tamayo P. 2015b. The molecular signatures database hallmark gene set collection. Cell systems 1:417-425.

Liu C, Su J, Yang F, Wei K, Ma J, and Zhou X. 2015. Compound signature detection on LINCS L1000 big data. Mol Biosyst 11:714-722. 10.1039/c4mb00677a

Maitin-Shepard J, Cusumano-Towner M, Lei J, and Abbeel P. 2010. Cloth grasp point detection based on multiple-view geometric cues with application to robotic towel folding. Robotics and Automation (ICRA), 2010 IEEE International Conference on: IEEE. $p$ 2308-2315.

Mav D, Shah RR, Howard BE, Auerbach SS, Bushel PR, Collins JB, Gerhold DL, Judson RS, Karmaus AL, and Maull EA. 2018. A hybrid gene selection approach to create the $\mathrm{S} 1500+$ targeted gene sets for use in high-throughput transcriptomics. PLoS One 13:e0191105.

Merrick BA, Paules RS, and Tice RR. 2015. Intersection of toxicogenomics and high throughput screening in the Tox21 program: an NIEHS perspective. International journal of biotechnology 14:7-27. 
626

627

628

629

630

631

632

633

634

635

636

637

638

639

640

641

642

643

644

645

646

647

648

649

650

651

652

653

654

655

656

657

658

659

660

661

662

663

664

665

666

667

668

669

670

671

Necsulea A, Soumillon M, Warnefors M, Liechti A, Daish T, Zeller U, Baker JC, Grutzner F, and Kaessmann H. 2014. The evolution of lncRNA repertoires and expression patterns in tetrapods. Nature 505:635-640. 10.1038/nature12943

Nguyen C, Wang Y, and Nguyen HN. 2013. Random forest classifier combined with feature selection for breast cancer diagnosis and prognostic. Journal of Biomedical Science and Engineering 6:551.

Qi Y. 2012. Random forest for bioinformatics. Ensemble machine learning: Springer, 307-323. Saetta M, Mariani M, Panina-Bordignon P, Turato G, Buonsanti C, Baraldo S, Bellettato CM, Papi A, Corbetta L, Zuin R, Sinigaglia F, and Fabbri LM. 2002. Increased expression of the chemokine receptor CXCR3 and its ligand CXCL10 in peripheral airways of smokers with chronic obstructive pulmonary disease. Am J Respir Crit Care Med 165:1404-1409.

Sahu B, and Mishra D. 2012. A novel feature selection algorithm using particle swarm optimization for cancer microarray data. Procedia Engineering 38:27-31.

Santoni FA, Hartley O, and Luban J. 2010. Deciphering the code for retroviral integration target site selection. PLoS computational biology 6:e1001008.

Smyth GK. 2005. Limma: linear models for microarray data. Bioinformatics and computational biology solutions using $R$ and Bioconductor: Springer, 397-420.

Soufan O, Ba-alawi W, Afeef M, Essack M, Rodionov V, Kalnis P, and Bajic VB. 2015a. Mining Chemical Activity Status from High-Throughput Screening Assays. PLoS One 10:e0144426. 10.1371/journal.pone.0144426

Soufan O, Kleftogiannis D, Kalnis P, and Bajic VB. 2015b. DWFS: a wrapper feature selection tool based on a parallel genetic algorithm. PLoS One 10:e0117988. 10.1371/journal.pone.0117988

Subramanian A, Narayan R, Corsello SM, Peck DD, Natoli TE, Lu X, Gould J, Davis JF, Tubelli AA, Asiedu JK, Lahr DL, Hirschman JE, Liu Z, Donahue M, Julian B, Khan M, Wadden D, Smith IC, Lam D, Liberzon A, Toder C, Bagul M, Orzechowski M, Enache OM, Piccioni F, Johnson SA, Lyons NJ, Berger AH, Shamji AF, Brooks AN, Vrcic A, Flynn C, Rosains J, Takeda DY, Hu R, Davison D, Lamb J, Ardlie K, Hogstrom L, Greenside P, Gray NS, Clemons PA, Silver S, Wu X, Zhao WN, Read-Button W, Wu X, Haggarty SJ, Ronco LV, Boehm JS, Schreiber SL, Doench JG, Bittker JA, Root DE, Wong B, and Golub TR. 2017. A Next Generation Connectivity Map: L1000 Platform and the First 1,000,000 Profiles. Cell 171:1437-1452 e1417. 10.1016/j.cell.2017.10.049

Thomas RS, Bahadori T, Buckley TJ, Cowden J, Deisenroth C, Dionisio KL, Frithsen JB, Grulke CM, Gwinn MR, Singh A, Richard AM, Williams AJ, Deisenroth C, Grulke CM, Patlewicz G, Shah I, Cowden J, Wambaugh JF, Harrill JA, Paul-Friedman K, Houck KA, Gwinn MR, Linnenbrink M, Setzer RW, Sams R, Judson RS, Simmons SO, Knudsen TB, Thomas RS, Lambert JC, Bahadori T, Swank A, Wetmore BA, Ulrich EM, Sobus JR, Phillips KA, Dionisio KL, Isaacs KK, Strynar M, Tornero-Valez R, Newton SR, Buckley TJ, Frithsen JB, Villeneuve DL, Hunter ES, III, Simmons JE, Higuchi M, Hughes MF, Padilla S, Shafer TJ, and Martin TM. 2019. The next generation blueprint of computational toxicology at the U.S. Environmental Protection Agency. 10.1093/toxsci/kfz058

Thomas RS, Wesselkamper SC, Wang NCY, Zhao QJ, Petersen DD, Lambert JC, Cote I, Yang L, Healy E, and Black MB. 2013. Temporal concordance between apical and transcriptional points of departure for chemical risk assessment. toxicological sciences 134:180-194.

Peer) reviewing PDF | (2019:06:38961:2:0:NEW 28 Sep 2019) 
672 Tolosi L, and Lengauer T. 2011. Classification with correlated features: unreliability of feature

673

674

675

676

677

678

679

680

681

682

683

684

685

686 ranking and solutions. Bioinformatics 27:1986-1994. 10.1093/bioinformatics/btr300 van Dam S, Vosa U, van der Graaf A, Franke L, and de Magalhaes JP. 2018. Gene co-expression analysis for functional classification and gene-disease predictions. Brief Bioinform 19:575-592. 10.1093/bib/bbw139

Van Dongen S, and Abreu-Goodger C. 2012. Using MCL to extract clusters from networks. Bacterial Molecular Networks: Springer, 281-295.

Villeneuve DL, and Garcia-Reyero N. 2011. Vision \& strategy: Predictive ecotoxicology in the 21st century. Environ Toxicol Chem 30:1-8. 10.1002/etc.396

Wang Y, Coleman-Derr D, Chen G, and Gu YQ. 2015. OrthoVenn: a web server for genome wide comparison and annotation of orthologous clusters across multiple species. Nucleic Acids Res 43:W78-84. 10.1093/nar/gkv487

Yang L, Allen BC, and Thomas RS. 2007. BMDExpress: a software tool for the benchmark dose analyses of genomic data. BMC genomics 8:387. 


\section{Figure 1}

Framework of the T1000 approach for gene selection and prioritization.

Phase I is composed of Steps [1-3]. After data is prepared in Step 1, the co-expression network is generated through Step 2. The prior knowledge scores are computed using (KEGG, MSigDB) and toxicological (CTD) relevance graphs in Step 3. Phase II involves Step 4 for reweighting of the co-expression scores based on prior knowledge of biological and toxicological relevance graphs. In addition, the graph is clustered during Step 4. In Phase III, in Step 5, a prediction model is trained for each cluster. Then, after selecting top genes from each cluster in Step 5, a one final prediction model called global is trained to rank all selected genes (Step 6). Phase IV is a focused on external evaluation of the prioritized gene list.
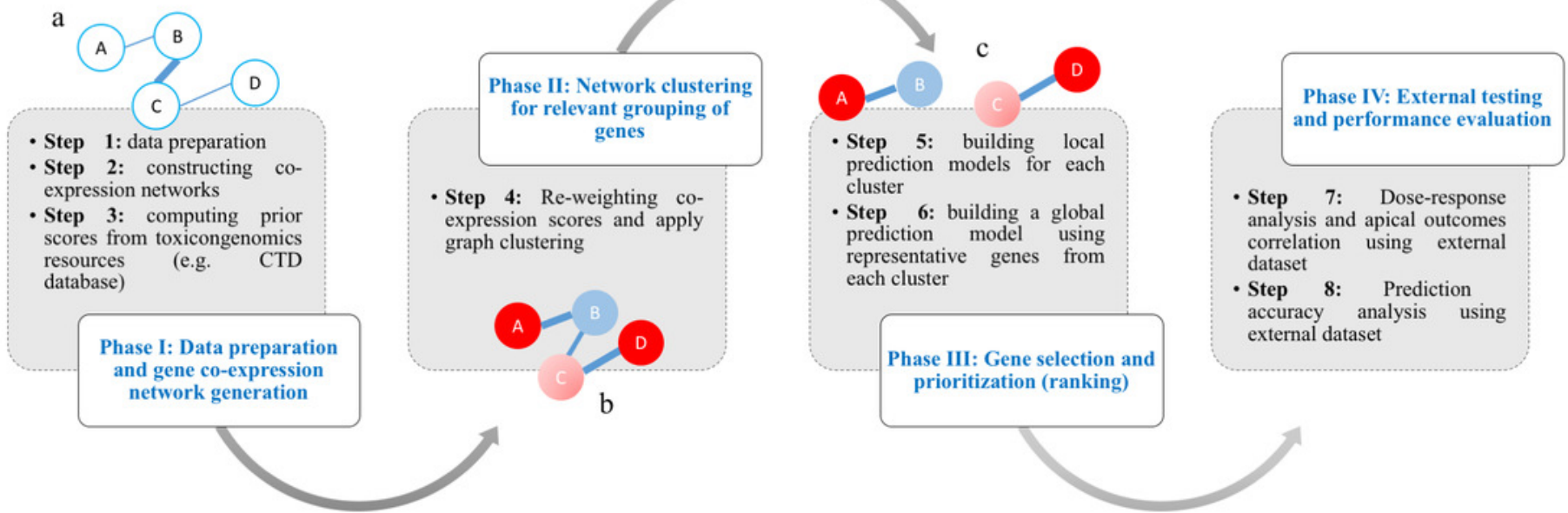

Datasets used for each phase Phase I \& Phase II

\section{Co-expression networks}

Open TG-GATEs (human in vitro liver, rat in vitro liver \& rat in vivo liver)

Prior scores

KEGG, Hallmark \& CTD

Phase III

Train

Open TG-GATEs (human in

vitro liver, rat in vitro liver

\& rat in vivo liver)

\section{Phase IV}

Test

Open TG-GATEs (rat in vivo kidney)

NTP (rat in vivo liver, bladder

\& thyroid) 


\section{Figure 2}

Visual representation of co-expression networks before and after performing Steps 2 and 3 of the T1000 selection process.

Visual representation of co-expression networks before and after performing Steps 2 and 3 of the T1000 selection process. A sample co-expression network of a group of 150 genes such that each pair of genes would have a connection is provided in Part (a). After re-weighting the correlation scores using the prior knowledge of biological and toxicological relevance graphs and performing clustering through Steps [1-4] of T1000 framework (see Figure 1), the graph in Part (a) is evolved to the one in Part (b). In Part (b), a pair of genes would have a link only if they hold enough confidence after applying prior scores. From part (b), nodes representing genes gain different levels of colors summarizing different levels of structural representations in the graph. Therefore, it is more relevant to cluster the graph at this stage after applying prior weights instead of the stage of Part (a). We can visually detect two separate clusters of genes in Part (b). After executing T1000 framework, we visualize the generated co-expression graph of all selected 1000 genes in Part (c). Compared to Part (a), we see variant levels of colors indicating different structural relevance. The colors in Parts (a), (b), and (c) reflect structural statistics using betweenness centrality and node degree. Part (a) holds a very similar statistics while Parts (b), (c) exploits and shows variant levels. A more contributing gene would have a larger node and a darker blue color while a less important one would have a very small node with a red color intensity. Please note that Parts (b) and (c) are realized only after executing steps from T1000 framework while Part (a) shows the generic representation of the co-expression graph. 
a) Co-expression network of a group of genes before clustering

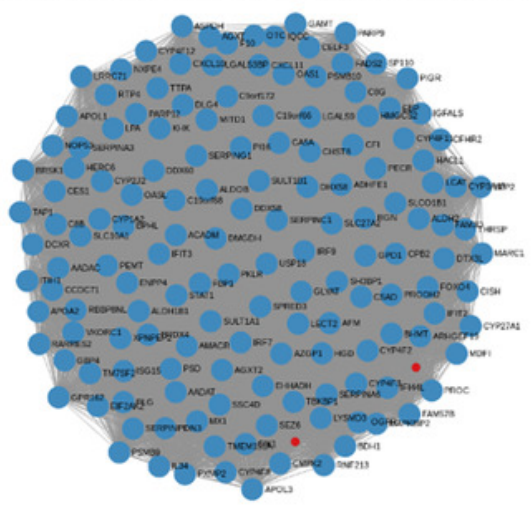

b) Co-expression network after applying prior weights and clustering

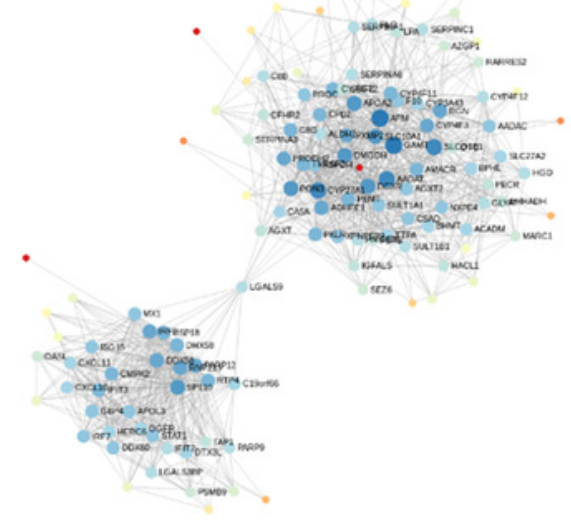

c) T1000 generated co-expression network after clustering

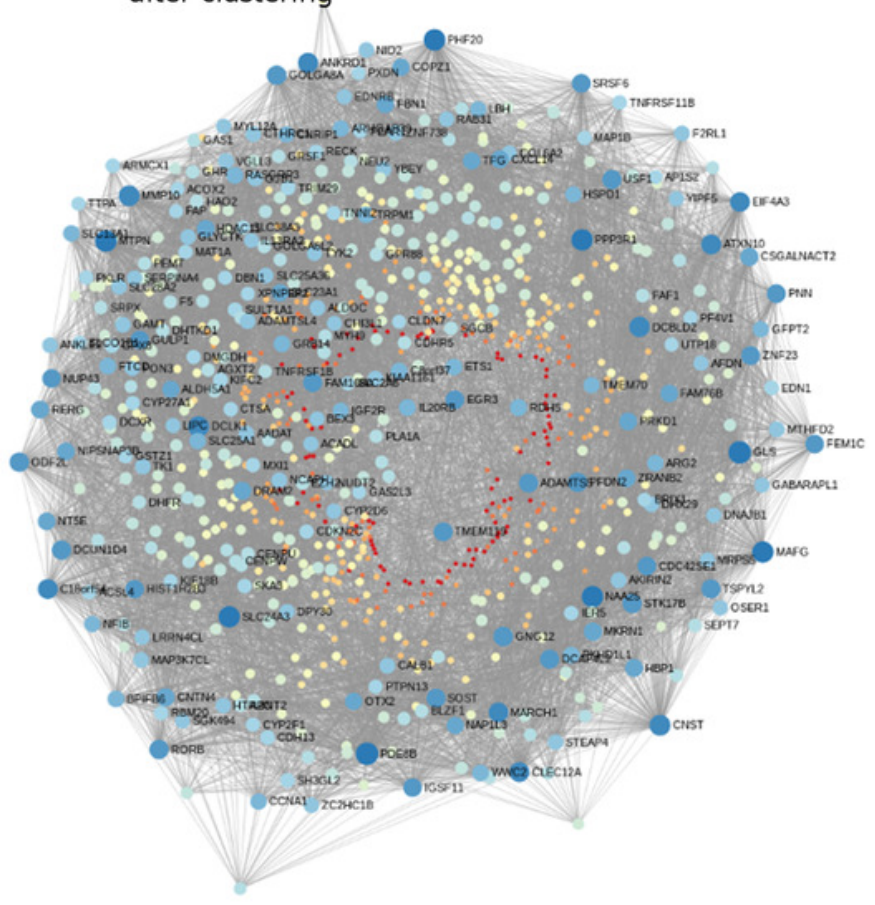




\section{Figure 3}

Ratios of BMDt/BMDa for each experimental group determined with various gene sets as indicated atop the plots.

Ratios of BMDt/BMDa represents ratio of transcriptionally-derived benchmark doses BMDt using gene signatures to apical outcome-derived benchmark dose BMDa serving as the ground truth. The limits of the blue rectangular band and dotted lines represent 3-fold and 10-fold of unity, respectively. Ratios could not be calculated for three experimental groups (hydrazobenzene (HZBZ): 5 day, 2 week, 4 week) due to a lack of apical outcomes. Red circles represent mean ratios greater than 10 -fold, while the yellow ones represent ratios greater than 3-fold. The fewer circles, the more the gene set is indicative of potential relevance to the examined apical endpoints (see Supplementary Figure 3 and 4 for T384 and T1500 plots, respectively). In Part a), the T1000 results are highlighted such that in only two experiments, the ratio of difference from the ground truth was greater than 3 folds and less than 10. In Parts b,c\&d, the results of L1000, S1500 and Limma are illustrated, respectively, with each having a single experiment (i.e., red circle) with 10-fold difference from the ground truth. All of them had more yellow circles as compared to Part a of T1000. 
a) T1000 Ratios

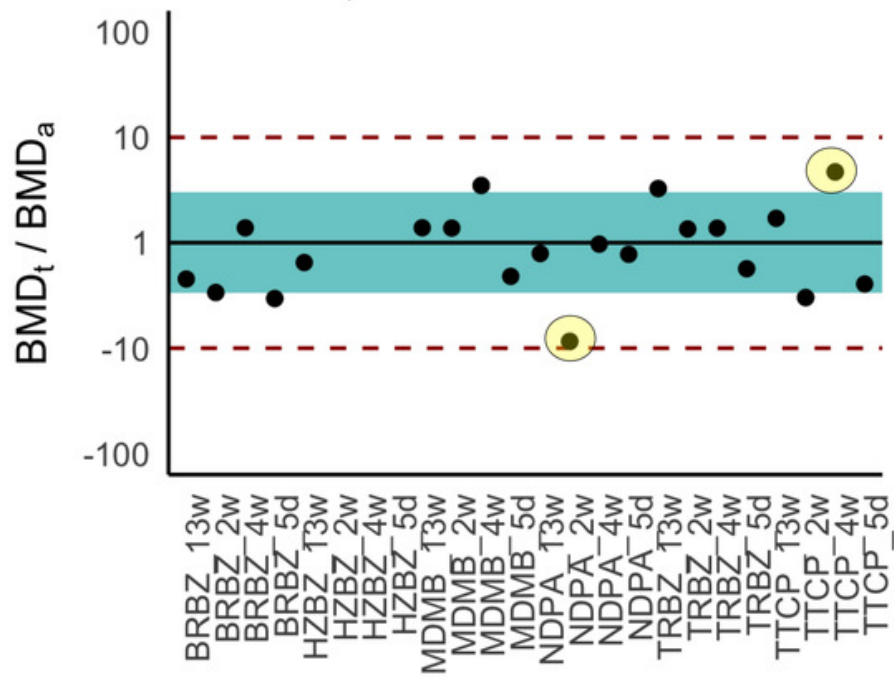

c) S1500 Ratios

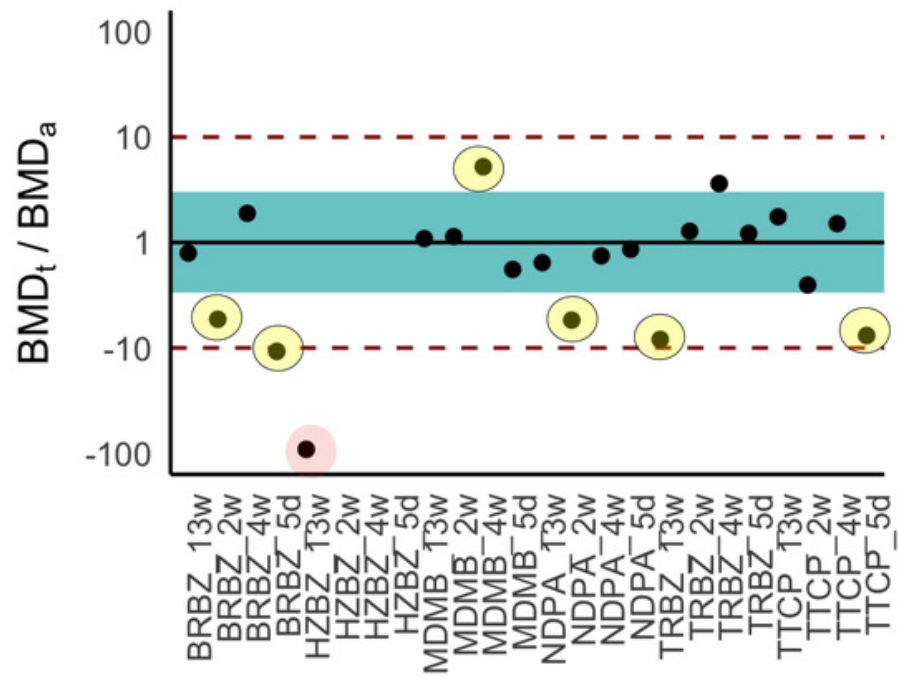

b) L1000 Ratios

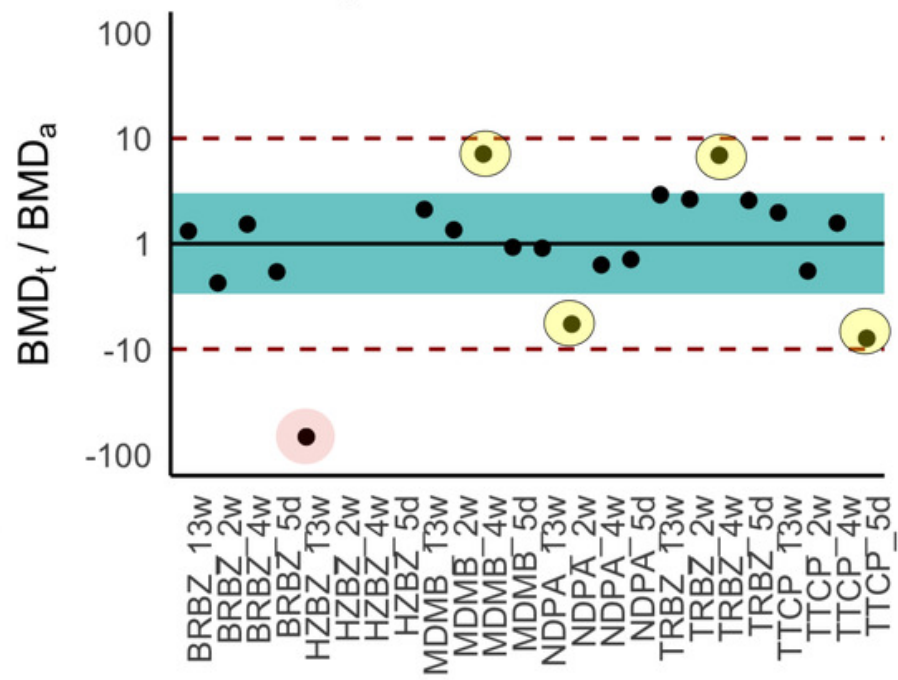

d) Limma Ratios

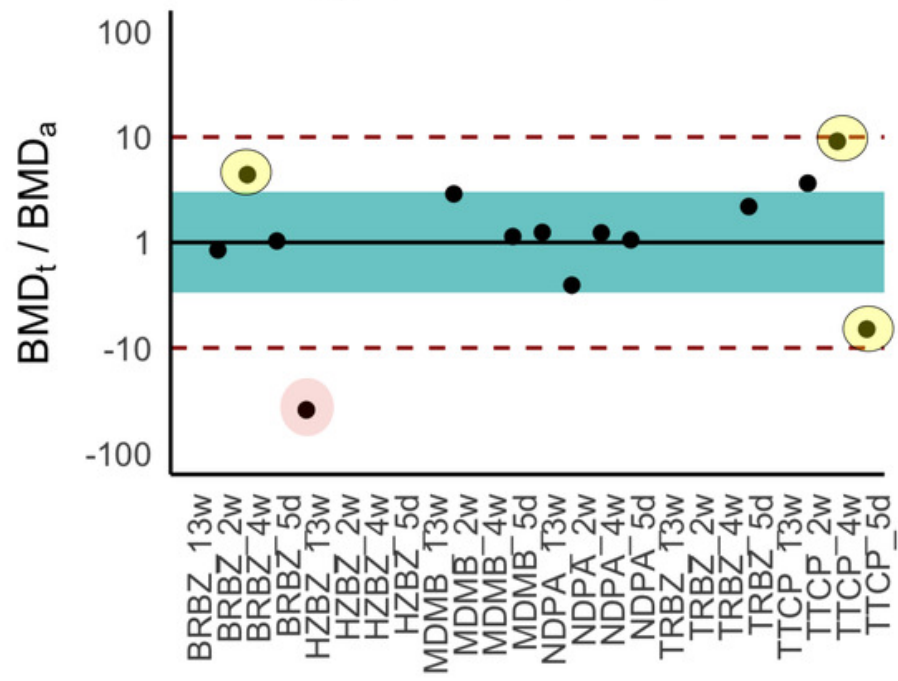




\section{Table $\mathbf{1}$ (on next page)}

Summary of datasets used in the current study.

Datasets 1-3 were used to develop T1000 (see Phase I, II \& III in Methods Section) and datasets 4 and 5 (see Phase IV in Methods Section) were used to evaluate the performance of the gene sets. 
1

\begin{tabular}{|c|c|c|c|c|c|c|c|}
\hline $\begin{array}{l}\text { Dataset } \\
\#\end{array}$ & Dataset & Organism & Organ & $\begin{array}{l}\text { Exposure } \\
\text { Type }\end{array}$ & $\begin{array}{l}\text { Number of } \\
\text { chemicals }\end{array}$ & $\begin{array}{l}\text { Matrix size (\% } \\
\text { missing values) }\end{array}$ & $\begin{array}{l}\text { Purpose in } \\
\text { Current Study }\end{array}$ \\
\hline 1 & $\begin{array}{l}\text { Open } \\
\text { TG- } \\
\text { GATEs }\end{array}$ & Human & Liver & in vitro & $\begin{array}{l}158 \\
\text { chemicals }\end{array}$ & $\begin{array}{l}2,606 \text { experiments } \mathrm{x} \\
20,502 \text { genes }(8.9 \%)\end{array}$ & Training \\
\hline 2 & $\begin{array}{l}\text { Open } \\
\text { TG- } \\
\text { GATEs }\end{array}$ & Rat & Liver & in vitro & $\begin{array}{l}145 \\
\text { chemicals }\end{array}$ & $\begin{array}{l}3,371 \text { experiments } x \\
14,468 \text { genes }(11.6 \%)\end{array}$ & Training \\
\hline 3 & $\begin{array}{l}\text { Open } \\
\text { TG- } \\
\text { GATEs }\end{array}$ & Rat & Liver & $\begin{array}{l}\text { in vivo } \\
\text { (single } \\
\text { dose) }\end{array}$ & $\begin{array}{l}158 \\
\text { chemicals }\end{array}$ & $\begin{array}{l}857 \text { experiments } x \\
14,400 \text { genes }(11.5 \%)\end{array}$ & Training \\
\hline 4 & $\begin{array}{l}\text { Open } \\
\text { TG- } \\
\text { GATEs }\end{array}$ & Rat & Kidney & $\begin{array}{l}\text { in vivo } \\
\text { (single } \\
\text { dose) }\end{array}$ & $\begin{array}{l}41 \\
\text { chemicals }\end{array}$ & $\begin{array}{l}308 \text { experiments } \mathrm{x} \\
14,400 \text { genes }(12.2 \%)\end{array}$ & Testing \\
\hline 5 & $\begin{array}{l}\begin{array}{l}\text { Dose- } \\
\text { response } \\
(G S E 45\end{array} \\
892)\end{array}$ & Rat & $\begin{array}{l}\text { Liver, } \\
\text { Bladder, } \\
\text { Thyroid }\end{array}$ & $\begin{array}{l}\text { in vivo } \\
\text { (repeated } \\
\text { dose) }\end{array}$ & 6 chemicals & $\begin{array}{l}30 \text { experiments } x \\
14,400 \text { genes }(0 \%)\end{array}$ & $\begin{array}{l}\text { Testing } \\
\text { (external } \\
\text { validation) }\end{array}$ \\
\hline Total & & & & & & 7,172 experiments & \\
\hline
\end{tabular}




\section{Table 2 (on next page)}

Descriptive comparison of T1000 against existing gene sets.

For the 'selection criteria' column, expression space coverage refers to the goal of finding a subset of genes that would achieve high correlation with the original full set of genes.Pathway coverage refers to finding a subset of genes that cover more pathways in a reference library. 
1

\begin{tabular}{|l|l|l|l|l|l|l|}
\hline $\begin{array}{l}\text { Gene } \\
\text { set }\end{array}$ & $\begin{array}{l}\text { Selection } \\
\text { criteria }\end{array}$ & $\begin{array}{l}\text { Ranked } \\
\text { gene list }\end{array}$ & Species & Data & Approach & $\begin{array}{l}\text { Number } \\
\text { of genes }\end{array}$ \\
\hline L1000 & $\begin{array}{l}\text { Expression } \\
\text { space coverage }\end{array}$ & No & Human & L1000 data & $\begin{array}{l}\text { PCA and clustering (Data } \\
\text { mining) }\end{array}$ & 978 \\
\hline $\begin{array}{l}\text { S1500 } \\
\text { (NTP } \\
\text { coverage that } \\
\text { combines data- } \\
\text { driven and } \\
\text { knowledge- } \\
\text { driven }\end{array}$ & No & Human & $\begin{array}{l}\text { Public GEO } \\
\text { expression datasets } \\
\text { (mainly GEO 3339 } \\
\text { gene expression } \\
\text { series) }\end{array}$ & $\begin{array}{l}\text { PCA, clustering, and } \\
\text { other data-driven steps } \\
\text { (Data mining) }\end{array}$ & $\begin{array}{l}\text { (Dincludes } \\
\text { (inclion } \\
\text { genes) }\end{array}$ \\
\hline T1000 & $\begin{array}{l}\text { Toxicological } \\
\text { relevance using } \\
\text { endpoint } \\
\text { prediction }\end{array}$ & Yes & $\begin{array}{l}\text { Human } \\
\text { and Rat }\end{array}$ & $\begin{array}{l}\text { Open TG-GATEs that } \\
\text { is founded on co- } \\
\text { expression networks } \\
\text { from CTD, KEGG } \\
\text { and Hallmark }\end{array}$ & $\begin{array}{l}\text { Co-expression network } \\
\text { and prior knowledge } \\
\text { (Graph mining). PCA and } \\
\text { clustering are used only } \\
\text { for the prior knowledge. }\end{array}$ & 1000 \\
\hline
\end{tabular}

2 


\section{Table 3(on next page)}

Summary of correlation of apical endpoints to 24 experimental groups ( 6 chemicals $\times 4$ exposure durations). 
1

\begin{tabular}{|c|c|c|c|c|c|c|}
\hline & $\begin{array}{l}\text { T384 (n } \\
=384)\end{array}$ & $\begin{array}{l}\text { T1000 (n } \\
=1000)\end{array}$ & $\begin{array}{l}\text { T1500 (n } \\
=1500)\end{array}$ & $\begin{array}{l}\text { L1000 (n } \\
=976)\end{array}$ & $\begin{array}{l}\text { S1500 (n } \\
=2861)\end{array}$ & $\begin{array}{l}\text { Limma } \\
(\mathrm{n}= \\
1000)\end{array}$ \\
\hline$\#$ of $\mathrm{BMD}_{t} \mathrm{~s}$ & 18 & 21 & 21 & 21 & 21 & 14 \\
\hline $\begin{array}{l}\text { Mean ratio } \\
\left(\mathrm{BMD}_{\mathrm{t}} / \mathrm{BMD}_{\mathrm{a}}\right)\end{array}$ & 2.2 & 1.2 & 1.1 & 1.8 & 1.1 & 2.1 \\
\hline $\begin{array}{l}\text { Correlation } \\
\left(\mathrm{BMD}_{\mathrm{t}},\right. \\
\left.\mathrm{BMD}_{\mathrm{a}}\right)\end{array}$ & $\begin{array}{l}0.83 \\
(p< \\
0.001)\end{array}$ & $\begin{array}{l}\mathbf{0 . 8 9} \\
(p< \\
0.001)\end{array}$ & $\begin{array}{l}0.83 \\
(p< \\
0.001)\end{array}$ & $\begin{array}{l}0.76 \\
(p< \\
0.001)\end{array}$ & $\begin{array}{l}0.78 \\
(p< \\
0.001)\end{array}$ & $\begin{array}{l}0.73 \\
(p<0.01)\end{array}$ \\
\hline
\end{tabular}

2 


\section{Table 4 (on next page)}

Summary comparison of average classification performance using the testing RatKidney dataset. Scores are based on average results from five classifiers (LDA, NBC, QDA, DT and RF) and the standard deviation is reported to highlight variance of estimate.

*Statistically significant at an alpha level of 0.1 using T-test and considering comparison with Random results. 
1

\begin{tabular}{|c|c|c|c|c|c|c|}
\hline & Sensitivity & Specificity & Precision & Gmean & F1Measure & F0.5Measure \\
\hline $\mathrm{T} 1000$ & $\begin{array}{c}29.25 \% \\
( \pm 11.64) \%\end{array}$ & $\begin{array}{l}71.33 \% \\
( \pm 4.74)\end{array}$ & $\begin{array}{l}21.51 \% \\
( \pm 4.45)\end{array}$ & $\begin{array}{l}44.7 \% \\
( \pm 7.8)^{*}\end{array}$ & $\begin{array}{l}24.58 \% \\
( \pm 7.11)^{*}\end{array}$ & $\begin{array}{l}22.6 \% \\
( \pm 5.36)\end{array}$ \\
\hline Limma & $\begin{array}{l}27.76 \% \\
( \pm 16.3) \\
\end{array}$ & $\begin{array}{l}70.75 \% \\
( \pm 6.33)\end{array}$ & $\begin{array}{c}20 \% \\
( \pm 9.96)\end{array}$ & $\begin{array}{l}41.84 \% \\
( \pm 14.81)\end{array}$ & $\begin{array}{l}22.99 \% \\
( \pm 12.04)\end{array}$ & $\begin{array}{l}21.06 \% \\
( \pm 10.64)\end{array}$ \\
\hline $\mathrm{CD}$ & $\begin{array}{r}21.79 \% \\
( \pm 15.39)\end{array}$ & $\begin{array}{c}68.08 \% \\
( \pm 10.97)\end{array}$ & $\begin{array}{l}13.94 \% \\
( \pm 6.64)\end{array}$ & $\begin{array}{l}34.79 \% \\
( \pm 13.3) \\
\end{array}$ & $\begin{array}{l}16.65 \% \\
( \pm 9.96) \\
\end{array}$ & $\begin{array}{l}14.83 \% \\
( \pm 7.82)\end{array}$ \\
\hline L1000 & $\begin{array}{l}22.99 \% \\
( \pm 12.82)\end{array}$ & $\begin{array}{l}70.42 \% \\
( \pm 5.78)\end{array}$ & $\begin{array}{l}16.84 \% \\
( \pm 7.29)\end{array}$ & $\begin{array}{c}38.33 \% \\
( \pm 11.46)\end{array}$ & $\begin{array}{l}19.27 \% \\
( \pm 9.27)\end{array}$ & $\begin{array}{l}17.71 \% \\
( \pm 7.97)\end{array}$ \\
\hline S1500 & $\begin{array}{l}21.79 \% \\
( \pm 7.65) \\
\end{array}$ & $\begin{array}{l}72.67 \% \\
( \pm 3.98)^{*}\end{array}$ & $\begin{array}{l}17.87 \% \\
( \pm 3.99)\end{array}$ & $\begin{array}{c}39.19 \% \\
( \pm 6.2) \\
\end{array}$ & $\begin{array}{l}19.53 \% \\
( \pm 5.42)\end{array}$ & $\begin{array}{l}18.48 \% \\
( \pm 4.48) \\
\end{array}$ \\
\hline Random-500 & $\begin{array}{l}27.83 \% \\
( \pm 11.69) \\
\end{array}$ & $\begin{array}{l}70.89 \% \\
( \pm 5.09)\end{array}$ & $\begin{array}{l}20.31 \% \\
( \pm 4.89)\end{array}$ & $\begin{array}{l}42.81 \% \\
( \pm 8.38)\end{array}$ & $\begin{array}{l}18.41 \% \\
( \pm 12.03)\end{array}$ & $\begin{array}{l}21.29 \% \\
( \pm 5.79)\end{array}$ \\
\hline $\begin{array}{l}\text { P-value } \\
\text { (T1000 vs. } \\
\text { Random) }\end{array}$ & 0.0555 & 0.3454 & 0.1283 & 0.0504 & 0.0192 & 0.1112 \\
\hline $\begin{array}{c}\text { Best Model } \\
\text { (Limma NBC) }\end{array}$ & $44.78 \%$ & $68.75 \%$ & $28.57 \%$ & $55.48 \%$ & $34.88 \%$ & $30.80 \%$ \\
\hline $\begin{array}{c}\text { Worst Model } \\
\text { (Limma_QDA) }\end{array}$ & $4.48 \%$ & $72.08 \%$ & $4.29 \%$ & $17.97 \%$ & $4.38 \%$ & $4.32 \%$ \\
\hline
\end{tabular}

